\title{
Topologia dos backbones de internet no Brasil
}

\author{
Internet backbone topology in Brazil
}

\author{
Marcelo Paiva da Motta \\ Geógrafo, Coordenação de Geografia do IBGE \\ marcelo.motta@ibge.gov.br
}

Artigo recebido em 24/08/2011 e aceito para publicação em 01/03/2012

\begin{abstract}
Resumo:: $\quad$ Este artigo visa reafirmar o papel do espaço no estudo das Novas Tecnologias de Informação e Comunicação (NTICs). Examinamos a topologia dos backbones de internet no Brasil usando as ferramentas matemáticas da teoria dos grafos. Através do cálculo de índices de centralidade (proximidade e intermediação), bem como de outras técnicas quantitativas, as redes físicas que compõem a internet são relacionadas à rede urbana preexistente, mostrando que em suas características gerais o funcionamento da internet não subverte a geografia econômica do país, a despeito do ideário antigeográfico suscitado por parte da literatura sobre os impactos da tecnologia.
\end{abstract}

Palavras-chave: Topologia, backbones, internet, rede urbana, Brasil

\begin{abstract}
This paper aims to reassert the role of space in the study of the New Information and Communication Technologies (NICTs). We examine the internet backbone topology in Brazil using mathematical tools from graph theory. By calculating centrality indexes (closeness and betweeness) and other quantitative techniques as well, the physical networks that comprise the internet are compared to the existing urban network. We show that, in its general features, the spatial dimension of the internet does not subvert the previous economic geography, despite the anti-geographic bias raised by part of the literature on technology impacts.
\end{abstract}

Keywords: Topology, backbones, internet, urban network, Brazil

\section{INTRODUÇÃO}

As redes de telecomunicações têm uma longa história em sua influência sobre a organização das cidades, desde a invenção do telégrafo. O presente artigo é uma tentativa para compreender uma das dimensões espaciais da internet e sua relação com a hierarquia urbana preexistente. Focaremos o sentido básico de sua espacialidade, a da estrutura física que lhe dá existência material, que se encontra profundamente imbricada com o sistema urbano (MALECKI, 2002). Definimos a internet como redes interconectadas de computadores utilizando o protocolo padrão TCP/IP, não importando o tipo de equipamento.
A abertura para o público em geral tem em torno de 15 anos de história, apesar de a internet já existir algumas décadas antes disso. No Brasil, no período compreendido entre janeiro de 1995, quando a rede passou a operar comercialmente, até janeiro de 2008, o número de hosts, aumentou exponencialmente de cerca de oitocentos computadores online para aproximadamente catorze milhões e meio (ver http://cetic.br/). O crescimento foi vertiginoso, grosso modo dobrando o número de equipamentos em rede a cada dois anos a partir de 2003. Em 2008, cerca de $39 \%$ da população do país já tinha acessado a internet pelo menos uma vez na vida, valor que sobe para $43 \%$ quando consideradas apenas as áreas urbanas (PESQUISA SOBRE O USO..., 2010). 
Esta rede, da década de 90 a de 2000, progressivamente deixou de ser uma tecnologia obscura, voltada para especialistas do campo de ciência da computação ou para entusiastas de informática para fazer parte da mídia e da vida do cidadão comum. Sua natureza aberta levou a um fenômeno de realimentação positiva no qual os próprios usuários são responsáveis pelas inovações, de maneira não-coordenada e caótica. Quanto mais novos usuários ganhavam acesso a rede, mais feições inovadoras eram inventadas, aumentando a facilidade de utilização e tornando-a ainda mais atrativa.

Esse processo de rápida difusão, bem como o do surgimento de constante inovações trazendo facilidades cotidianas - serviços de comércio a domicílio, de requisição de documentos oficiais, consultas, redes sociais, redes de trocas de arquivos, jogo online etc. - parecem mascarar o fato de a internet ser uma rede bem ancorada no espaço, como qualquer outra que dependa de uma infraestrutura física.

A internet, à primeira vista, não parece ser um caso de estudo para o geógrafo. O chamado ciberespaço, noção que é frequentemente tomada como sinônimo da própria internet, é um campo puramente imaterial, na realidade uma metáfora do próprio espaço. Uma vez que se conecta à rede mundial de computadores, a distância não conta mais, as barreiras espaciais são vencidas e as fronteiras são ultrapassadas, já que sua instantaneidade e a ubiquidade fariam com que a geografia, tradicionalmente preocupada com diferenças espaciais, perdesse seu significado. A Internet, uma rede transterritorial, possibilita a troca de mensagens por todos e disponibiliza informações independentemente de sua localização, na proporção em que alguns fatores constrangedores, como o isolamento, as tarifas proporcionais à distância (para o usuário final) e os custos de deslocamento, deixam de ser importantes.

De fato, Éveno e Puel (2003) falam do ideário antigeográfico criado pelos discursos sobre os impactos das tecnologias da informação e da comunicação (TIC) sobre a sociedade. Uma questão comum em todas as obras analisadas por estes autores é a da contração do espaço e do fim das distâncias, na qual a análise espacial, quando presente, reduz o espaço a sua dimensão física ou euclidiana. Na rea- lidade, grande parte do interesse dos trabalhos sobre as novas tecnologias não é realmente o espaço, mas o seu desaparecimento.

Esse tipo de discurso era mais comum nos anos 90, quando a internet era em grande medida ainda desconhecida do grande público e seu impacto era superdimensionado. Largamente especulativos e pouco baseados em dados empíricos reais, aqueles trabalhos possuíam um tom "profético" ou revolucionário. Frances Cairncross (2000), em sua obra bastante conhecida, fala da morte da distância causada pelas telecomunicações. Considera que estaríamos no início de uma nova era histórica, na qual os serviços considerados locais, como educação, saúde, consultorias jurídicas e financeiras, passariam a ser ofertados globalmente, com enormes consequências para a sua democratização, tornando-os facilmente disponíveis paras as massas. Um outro exemplo desse tipo de discurso é o de Negroponte (1999), para quem o "mundo digital não tem um centro e, portanto, não tem periferia". Ele chega mesmo a considerar que as atividades humanas dependeram historicamente da concentração - nomeadamente a urbanização e a indústria - e que a internet e as comunicações por vias eletrônicas, ao torná-la prescindível, permitiriam que os negócios fossem geridos e múltiplas relações sociais se efetivassem fora dos grandes centros, em locais aprazíveis, o que traria uma ruralização da sociedade.

A despeito do otimismo que o crescimento da internet em todos os países suscitou, não favorecendo a abordagem geográfica, um olhar mais atento a seu funcionamento real mostra que muito pouco disto que foi descrito acima é possível e que ela espelha os processos materiais já existentes da sociedade. Embora seja, de fato, um instrumento potente de disseminação de informações as mais diversas e inusitadas, assim como de trocas entre pessoas fisicamente apartadas, a infraestrutura que a torna possível não está presente em todos os lugares. Mesmo quando há o contra-argumento de que basta possuir um computador, uma rede elétrica estável e uma linha telefônica para estar habilitado a conectar-se na rede, isto sozinho já exclui parcelas significativas do espaço, tanto na escala global - pense-se no caso da Áfri- 
ca - quanto na nacional, quando se leva em conta os municípios isolados da região Norte e áreas de renda mais deprimida no Nordeste. Além disso, o próprio termo "conexão" ganha um sentido nebuloso quando se considera que nada diz a respeito da sua qualidade, da largura de banda (que muda radicalmente a experiência de navegação), das habilidades do usuário, da frequência do uso etc.

Desde alguns anos, principalmente a partir de 2001, pesquisadores começaram a se debruçar mais sistematicamente sobre o tema. Há parcela significativa de geógrafos enfocando a espacialidade da rede e mostrando que a geografia tem nela um papel essencial (vide DODGE \& KITCHIN, 2001; ZOOK, 2001a, 2001b, 2005; MALECKI, 2002, DUPUY, 2002; 2004, entre outros). O presente trabalho se insere nessa linha buscando relacionar as redes de backbones - linhas de alta capacidade de transmissão de dados - da internet à rede urbana brasileira.

Optou-se pela análise da base infraestrutural que permite que a Internet funcione, nomeadamente as redes backbones. Segundo Malecki (apud TRANOS \& GILLESPIE, 2009), as redes backbone são definidas como sistemas autônomos que constituem o núcleo da Internet, essenciais para todas as interações entre computadores, exceto as locais. Considerando que a internet é formada pela interligação de inúmeras redes locais dispersas, os backbones são responsáveis pela conexões de longa distância entre elas. É um conjunto de caminhos entre as redes que, por agregar a maior parte do tráfego, empregam as maiores velocidades e capacidades de transmissão do conjunto. Em termos concretos, trata-se de redes de cabos de fibras óticas instaladas por firmas de telecomunicações e outras, que se estendem por milhares de quilômetros - o que dá seu caráter global. As diversas redes de longa distância se conectam entre si e com as redes locais, realizando trocas de tráfego de dados.

Cabe salientar que as diversas tecnologias de conexão, como wifi, redes $3 \mathrm{G}$ (através dos sinais de telefonia celular), Adsl, cabo coaxial e mesmo satélite dizem respeito à ligação individual, chamada pelo jargão do setor de telecomunicações de "última milha", realizada no varejo. Constituem-se em sub-redes "na ponta", interligando os usuários individuais localizados quer nas cidades, quer de forma dispersa, recebendo a infraestrutura de sua conexão de maneira capilar, nos bairros, ruas e aglomerações rurais. O papel do backbone é agregar o tráfego destas sub-redes, encaminhando-o a grandes distâncias e em grande volume. Todas as informações digitais geradas por essas sub-redes, ou as tendo como destino passarão necessariamente pelos backbones, que lhes são hierarquicamente superiores.

A dificuldade de obtenção de dados de tráfego devido ao segredo comercial que envolve as empresas prestadoras do serviço justificou a opção pelo enfoque na topologia das redes, como forma de analisar seu desenvolvimento, os lugares privilegiados em relação a ela, os seus relés e o atendimento aos mercados tais como são percebidos pelos operadores de telecomunicações.

A relevância desta temática se justifica pela crescente utilização de atividades intensivas em informação na economia atualmente. O momento histórico atual vê o aumento de importância das formas de organização social em rede. A emergência da globalização enquanto integração funcional de atividades dispersas, da acumulação flexível - substituição das linhas de produção fordistas por unidade descentralizadas, com subcontratação de pequenas e médias empresas - e do paradigma da tecnologia da informação têm nas redes, com sua propriedade de conexidade entre os nós, a base material para o seu próprio funcionamento (CASTELLS, 1999; DIAS, 1995). Os processos recentes de integração dos mercados por todo o planeta, de construção de fluxos financeiros globais e da integração das informações entre países, regiões e cidades ensejam a construção das infraestruturas físicas que dão forma às redes. Sua densificação é o pressuposto que viabiliza a crescente circulação de mercadorias e capitais, modificando as relações de espaço com o tempo.

Dado que os fluxos de capital, pessoas, ordens, tecnologia etc. passam a ser os estruturadores dominantes da sociedade, Castells (ibid.,p, 436) propõe o conceito de espaço de fluxos: $O$ espaço de fluxos é a organização material das práticas sociais de tempo compartilhado que funcio- 
nam por meio de fluxos. Em seu nível mais básico, o suporte material do espaço de fluxos é formado pela rede de impulsos eletrônicos que permite a coordenação de processos. No momento em que as cidades mais importantes mudam o cerne de suas economias, da produção física de bens para as atividades centradas na informação e conhecimento, elas emergem como os nós mais significativos nas redes de fluxo de dados, sendo os grandes mediadores no transporte de informações de uma economia global cada vez mais integrada (MOSS \& TOWSEND, 2000).

Nesse contexto, a Internet surge como o meio mais avançado, eficiente e versátil de distribuição e troca de informações, a ponto de ameaçar a imprensa escrita tradicional. O fato de ser uma tecnologia de uso geral, sem fim predeterminado, determina sua diversidade em abrigar um amplo escopo de conteúdos, até o momento fracamente regulamentado. Cabe, portanto, examinar na escala nacional a acessibilidade das cidades aos serviços de tráfego da internet de hierarquia mais alta.

\section{A TOPOLOGIA DOS BACKBONES NO BRASIL}

Os backbones, da maneira como foram aqui tratados representam uma aproximação com a realidade das infraestruturas físicas que dão existência à internet. São compostos por cabos de fibra ótica terrestre, de longa distância e alta capacidade de transmissão de dados, interconectando as cidades. Estão excluídas as redes metropolitanas, que só podem ser tratadas na escala local.

A partir dos mapas publicados no ATLAS BRASILEIRO DE TELECOMUNICAÇÕES (2009) foi confeccionada uma matriz de pares de ligações, constituída das conexões entre os municípios dois a dois. Sua arquitetura encontra-se na figura 1, considerando também a existência da RNP (Rede Nacional de Ensino e Pesquisa), rede pública que interconecta as universidades e outras instituições de ensino e pesquisa.

Dada a complexidade das redes de 16 diferentes companhias, envolvendo uma miríade de nós conectados a distâncias que vão desde a escala nacional à regional, é útil empregar ferramentas da teoria dos grafos para a compreensão de como as diferentes cidades relacionam-se entre si de acordo com a disponibilidade dessa infraestrutura. $\mathrm{O}$ instrumental da análise de redes vem se mostrando como um método difundido nos estudos de redes backbone, como demonstram os trabalho de Grubesic e O'Kelly (2002), Malecki (2002), Moss e Townsend (2000), Tranos e Gillespie (2009) e Wheeler e O'Kelly (1999). Com ele torna-se possível discernir os nós mais importantes daqueles que são periféricos, a existência de sub-redes, grupos de nós cujas ligações formam uma coesão maior entre si do que com o restante, e porções que ficariam isoladas em caso de desligamento de um ou mais nós.

A rede de backbones aqui tratada, RNP inclusive, é composta pela agregação das redes individuais de cada companhia de telecomunicações que atua no setor de fibras óticas de longa distância no país. Como o tráfego circula entre elas, formam uma única rede em escala nacional. É constituída por 243 nós, cada qual correspondendo simultaneamente a um ponto de presença da rede de cada empresa (o local físico onde estão os roteadores e demais equipamentos que fornecem o acesso à rede) e ao município onde se localiza. As conexões entre eles perfazem 565 pares de ligações, ilustrados na figura 2. O arco entre duas cidades pode conter ligações redundantes, caso diferentes empresas liguem o mesmo par de municípios, que, contudo, para melhor clareza na visualização, são representados apenas por um arco.

Buscou-se, na apresentação do grafo, eliminar o tanto quanto possível visões subjetivas e juízos antecipados. Para tanto, se utilizou o método automático proporcionado pelo algoritmo Fruchterman-Reingold, adequado para redes grandes, com centenas de nós (NOOY et al., 2005). Este método tenta minimizar a distância entre os vértices diretamente conectados, ao mesmo tempo em que separa partes desconexas da rede ou com menor número de ligações. Em geral, quanto mais no centro da figura, mais cada nó ou vértice particular possui ligações na rede ou, possuindo poucas ligações, está vinculado diretamente a um nó 
Figura 1 - Pares de ligações backbones no Brasil - 2008

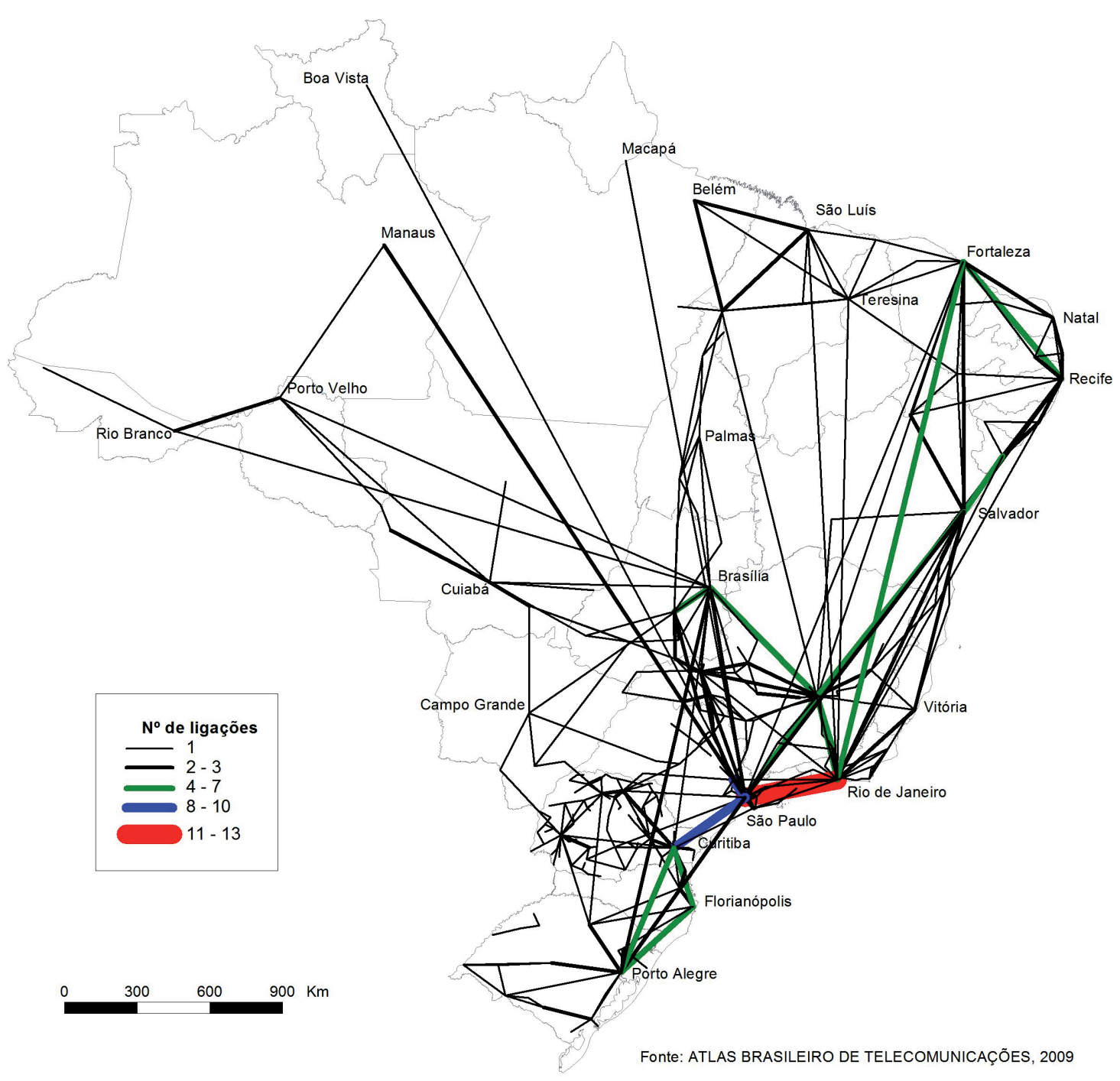

com um número ligações alto. Também podem assumir posição central nós que servem de ponte entre duas partes mais periféricas da rede, representadas em lados opostos do grafo. Os nós restantes tendem a tomar uma forma circular em torno do núcleo da rede. A partir do resultado automático, o ajuste fino da posição dos nós foi realizado manualmente.

São Paulo destaca-se como o nó com maior grau, isto é, o maior número de ligações diretas (73) em relação aos outros vértices. É seguido pelo Rio de Janeiro com 48, Belo Horizonte com 43, Curitiba com 37 e Brasília com 29.

Curiosamente, apesar de possuir menos ligações que Belo Horizonte, a capital paranaense tem posição mais central na rede, uma vez que possui um grande número empresas que realizam ligações diretas com São Paulo, o nó principal do conjunto da rede. Nesse sentido, Belo Horizonte pode ser caracterizado como um vértice de passagem entre as regiões Nordeste e Sudeste, de um lado, e o Nordeste e o Centro-Oeste, por outro, possuindo uma quantidade variada de ligações com outras capitais, enquanto Curitiba permanece com maior centralização em São Paulo.

Também é possível perceber nós com graus baixos ou relativamente baixos e que, entretanto, localizam-se mais próximos ao centro do grafo justamente por estarem ligados a pontos importantes, caso de Macapá e de Boa Vista, conectados diretamente a São Paulo pela RNP. 
Figura 2 - Topologia da rede de backbones

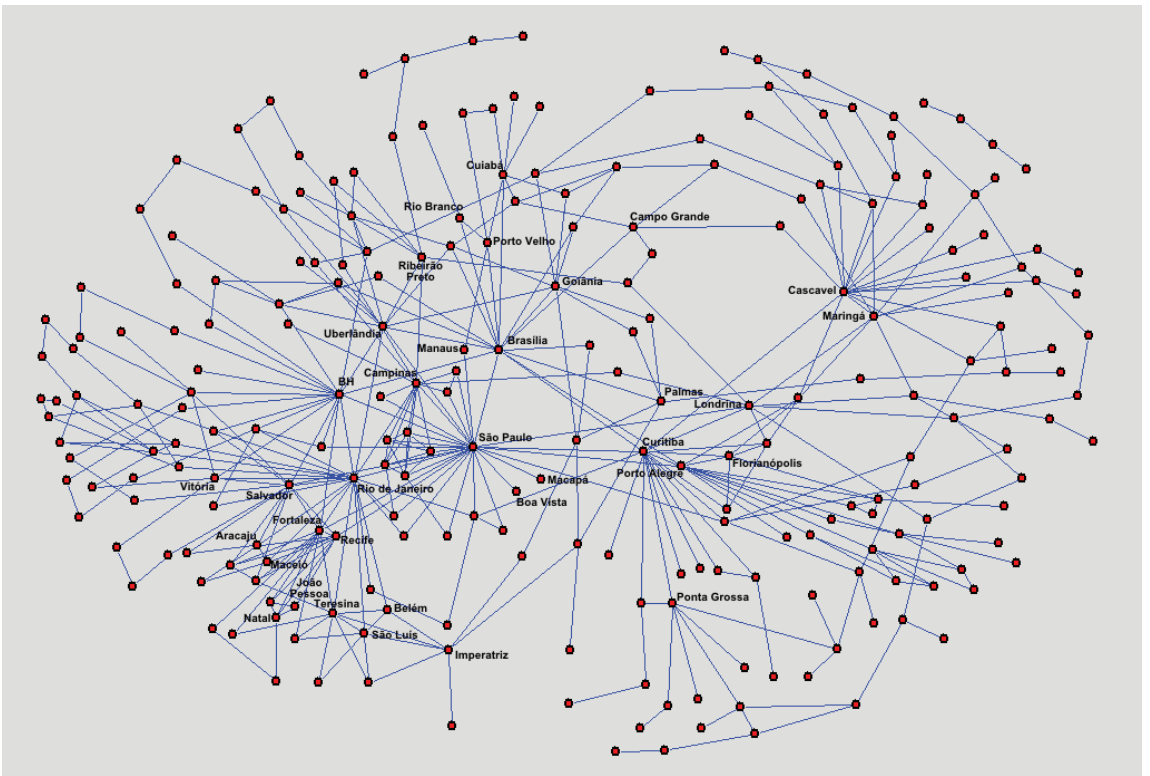

Fonte: Elaboração do autor, com base no ATLAS BRASILEIRO DE TELECOMUNICAÇÕES, 2009

Para avaliar o peso do backbone público na conformação geral desse tipo de rede, também foram produzidos grafos sem a presença da Rede Nacional de Pesquisas, o que levou a uma redução do número de vértices de 243 para 241 - correspondendo exatamente às capitais estaduais do Amapá e Roraima. A desconsideração da RNP afetou relativamente pouco o grau dos demais nós, reduzindo São Paulo para 63 e alçando Belo Horizonte para a segunda posição, com 40. Seguem-se o Rio de Janeiro com 39 e Curitiba com 35. Brasília foi a cidade mais afetada, caindo para 20 (de $5^{\text {a }}$ para a $9^{\text {a }}$ posição).

Apesar de indicar a importância dos vértices na rede, o simples exame do grau pouco diz sobre a maneira pela qual se inter-relacionam os nós. Basta olhar os casos de Florianópolis e Cascavel (PR), ambos com 17 ligações. A primeira cidade tem uma posição mais central, já que se liga a Porto Alegre e Curitiba, dois nós centrais para a conectividade da rede como um todo, como se verá mais adiante. Cascavel, por outro lado, está em uma posição mais periférica. Apesar de ligar-se diretamente a Curitiba, esse município possui um número grande de conexões com nós de "ponta de rede", isto é, que se conectam somente a esta cidade mesmo, ou possuem apenas mais um intermediário no caminho.

Para se ter uma noção do nível de centralização da rede, dos nós que têm acesso mais rápido e direto a todos os demais ou daqueles que são mais periféricos, uma técnica de interesse é o cálculo dos índices de proximidade (closeness) e de intermediação (betweenness). Levando-os em consideração, é possível avaliar cada nó individualmente em sua relação com o conjunto da rede.

O índice de proximidade (IP), medido para cada nó individualmente, baseia-se na distância total entre um vértice e os demais na rede. Quanto mais próximo um nó estiver de todos os demais, mais eficientemente os fluxos chegarão a ele. Cabe enfatizar que a noção de distância entre dois pontos em um grafo é o número de pares de ligações, ou passos, entre eles. $\mathrm{O}$ valor do índice para determinado nó da rede é calculado pelo número total de vértices dividido pela soma das distâncias entre este nó e todos os outros:

$$
I P\left(V_{a}\right)=\frac{T-1}{\sum D\left(V_{a} ; V_{n}\right)}
$$

onde $V$ representa os vértices, $T$ o número total de vértices e $D$ a distância entre o vértice $a$ e o 
vértice $n$, sendo $a \neq n$. O valor máximo do índice é de 1 , no caso, de um vértice estar diretamente conectado a todos os outros (o número de vértices será igual ao valor da soma das distâncias) (NOOY, et al., ibid.).

O segundo índice, o de intermediação (IIN), analisa o quanto cada nó está no caminho entre todos os demais. É calculado pelas medidas geodésicas, isto é, o percurso mais curto entre dois pontos da rede. O índice de intermediação de um nó é a proporção da medida geodésica entre todos os vértices da rede que incluem aquele nó. Em outras palavras, divide-se o número de caminhos curtos entre todos os vértices que incluam o nó em questão, por todos os que não o incluam:

$$
\operatorname{IIN}\left(V_{a}\right)=\frac{\sum G_{n x}\left(V_{a}\right)}{G_{n x}}
$$

onde $G$ representa o número de caminhos geodésicos, sendo $\mathrm{a} \neq n \neq x$.

Quanto maior o índice, mais importante aquele nó será para o conjunto da rede, pois os menores caminhos entre um grande número de vértices passam por ele. Um quadro comparativo da posição dos vértices com os maiores índices encontra-se no quadro 1.

Quadro 1 - Comparativo dos índices proximidade e intermediação

\begin{tabular}{|c|c|c|c|}
\hline \multicolumn{2}{|c|}{ Índice de proximidade } & \multicolumn{2}{|c|}{ Índice de intermediação } \\
\hline Município & Índice * 100 & Município & Índice * 100 \\
\hline 1 São Paulo & 36,98 & 1 São Paulo & 42,83 \\
\hline 2 Curitiba & 34,37 & 2 Curitiba & 32,48 \\
\hline 3 Brasília & 34,07 & 3 Rio de Janeiro & 19,26 \\
\hline 4 Belo Horizonte & 32,38 & 4 Brasília & 18,98 \\
\hline 5 Rio de Janeiro & 31,85 & 5 Cascavel & 18,55 \\
\hline 6 Uberlândia & 31,76 & 6 Belo Horizonte & 16,45 \\
\hline 7 Porto Alegre & 31,68 & 7 Londrina & 13,25 \\
\hline 8 Londrina & 31,13 & 8 Porto Alegre & 12,30 \\
\hline 9 Santos & 30,05 & 9 Ponta Grossa & 9,88 \\
\hline 10 Salvador & 29,90 & 10 Uberlândia & 8,59 \\
\hline 11 Fortaleza & 29,90 & 11 Maringá & 8,27 \\
\hline 12 Campinas & 29,63 & 12 Campinas & 6,63 \\
\hline 13 Guarapuaı & 29,30 & 13 Ribeirão Preto & 5,59 \\
\hline 14 Cascavel & 28,30 & 14 Salvador & 4,97 \\
\hline 15 Recife & 28,24 & 15 Goiânia & 4,21 \\
\hline 16 Varginha & 28,00 & 16 Fortaleza & 4,13 \\
\hline 17 São José dos Campos & 27,97 & 17 Figueira & 3,87 \\
\hline 18 Volta Redonda & 27,93 & 18 Paranavaí & 3,22 \\
\hline
\end{tabular}

Org. do autor.

São Paulo desponta com o maior valor de ambos os índices, seguido por Curitiba, que é o grande intermediador na região Sul. Brasília e Belo Horizonte, terceiro e quarto colocados no índice de proximidade são, respectivamente, quarto e sexto no de intermediação. Isto mostra que, embora possuam muitas conexões diretas com um grande número de nós, essas metrópoles são menos importante que o
Rio de Janeiro quanto ao papel de intermediário.

A cidade de Cascavel, quinta colocada no índice de intermediação, possui uma posição relativamente baixa no que diz respeito a centralidade de proximidade. Esse município, como já notado, liga-se diretamente a diversos vértices periféricos, o que lhe confere um valor mais baixo no primeiro índice. Porém, o caminho entre um número significativo de 
nós no estado do Paraná e o restante da rede passam, tanto por ele quanto por Curitiba, aumentando sua importância no papel de intermediação.

Na região Sul também despontam Londrina e Porto Alegre, com valores médios e ranking aproximadamente igual em ambos os índices, e Ponta Grossa, também como forte intermediador.

As capitais nordestinas têm em Salvador o ponto com maiores índices, que é condizente com sua posição na hierarquia urbana, seguida de Fortaleza e, mais abaixo, Recife.

Outras cidades, como Santos, Guarapuava, São José dos Campos e Volta Redonda constam na relação de municípios com índice de proximidade elevado em virtude de sua posição junto aos grandes centros urbanos nacionais. Essa mesma posição, por outro lado, causa um "efeito de sombra" no tocante à intermediação. Uma vez que estão próximos aos vértices mais importantes, eles são ignorados pelas ligações geodésicas da rede, tendo então índices de intermediação extremamente baixos (por exemplo, Santos encontra-se na $83^{\circ}$ posição).

Uma vez estabelecida a visão geral da topologia da rede, cabe buscar agrupamentos de vértices que são mais firmemente conectados entre si do que com o restante. No lugar de enfatizar o número de ligações de cada nó em particular, voltaremos nossa atenção para a existência de núcleos de vértices cujas ligações formam um sub-rede coesa, pois o grau (número de ligações) tomado isoladamente não informa se os nós com um determinado valor estão espalhados pela rede ou se formam aglomerações. Uma técnica que permite discernir sub-redes relativamente densas é o k-núcleo ( $k$-core) (NOOY et al., 2005), onde $k$ indica o grau mínimo de cada vértice que forma um núcleo coeso.

Há, assim, uma mudança de ênfase, do grau individual do vértice para o grau do grupo. Um k-núcleo de valor 3, por exemplo (denominado doravante de 3-núcleo), contém todos os vértices com no mínimo três vizinhos, que estão, por sua vez, ligados a vértices que também possuam no mínimo três ligações. Dessa forma, seleciona-se da rede um subconjunto máximo, no qual todos os vértices estão o mais próximo possível de estarem todos interconectados, atendendo ao critério escolhido (o número de ligações mínimo). Esse subgrupo então, não pode ter um

Figura 3 - Distribuição dos k-núcleos

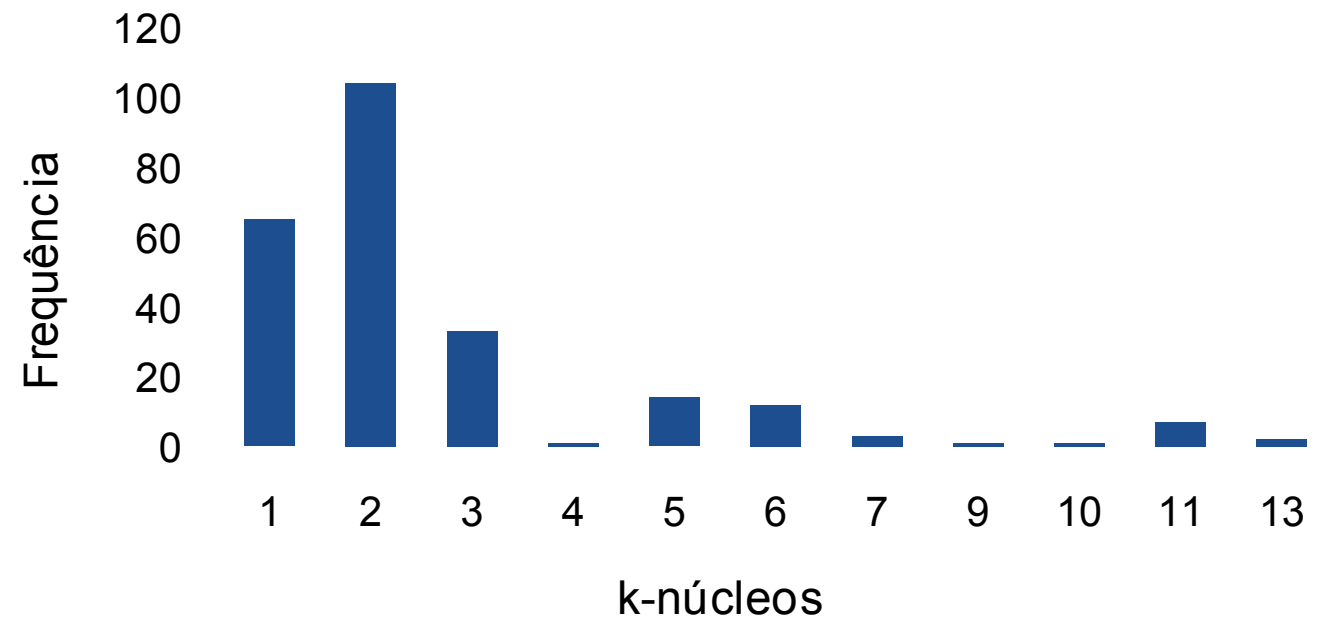

Soc. \& Nat., Uberlândia, ano 24 n. 1, 21-36, jan/abr. 2012 


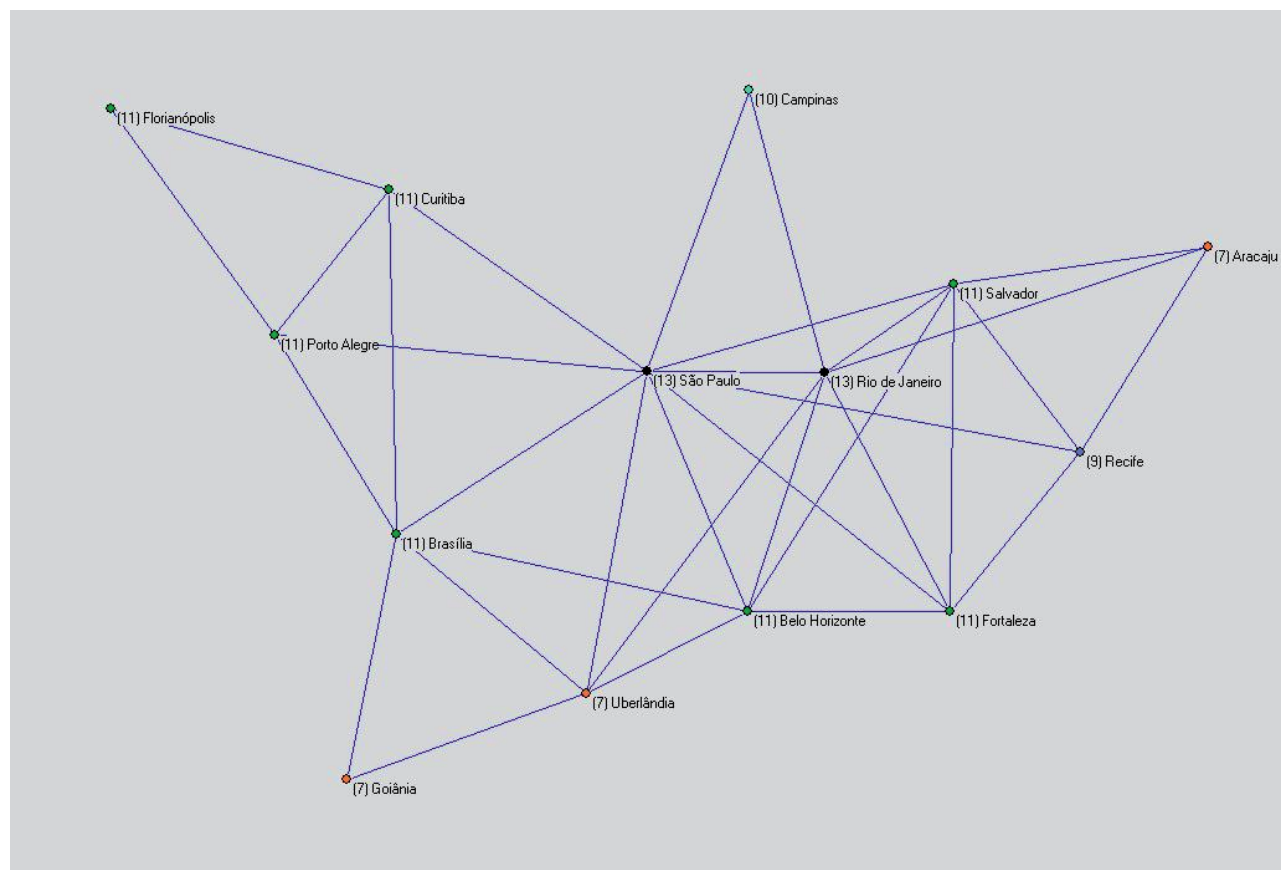

Fonte: Elaboração do autor, com base no

ATLAS BRASILEIRO DE TELECOMUNICAÇÕES, 2009

vértice adicionado sem alterar sua coesão interna seja porque todos os outros vértices têm graus menores do que, no caso, três, ou porque os que possuem este grau ou mais não se ligam diretamente a este núcleo.

Como a maioria dos vértices da rede de $b a$ ckbones aqui analisada encontra-se nos cores 1 e 2 (53,1\% dos vértices), sua eliminação facilita a visualização dos $k$-núcleos mais altos, aqueles nós com maior número de ligações e mais forte coesão.

$\mathrm{Na}$ presente rede, o grau máximo que forma uma sub-rede coesa é 13. Certamente, existem vários vértices com valores superiores a este, porém eles não atendem o critério exposto acima: não há vértices com graus superiores a este valor que se conectem a outros vértices semelhantes. De acordo com o histograma de distribuição do nós nas classes k-núcleo (Figura 3) é pequeno o número de vértices que atendem esse requisito, na realidade apenas Rio de Janeiro e São Paulo.

Assim, escolhemos aqueles pertencentes ao core 7 , patamar a partir do qual o número absoluto dos nós é reduzido e onde ocorre uma quebra de fre- quência, que justifica sua seleção como topo das sub-redes coesas. O 7-núcleo mostra uma rede altamente conectada, tendo como ponto focal a metrópole paulista (Figura 4). O k-núcleo agrupa não necessariamente os nós com exatamente o número selecionado de vizinhos, mas sim aqueles que possuem a quantidade de ligações escolhidas. É por esse motivo que o 13-core contém apenas Rio e São Paulo, pois apesar de serem apenas dois vértices, possuem 13 ligações um para com o outro.

O grafo deste subconjunto evidencia o cerne das redes de backbones no Brasil. Aqueles nós com alto número de conexões e forte coesão interna são, como era de se esperar, as metrópoles principais, além de algumas cidades de porte médio, como Uberlândia e Florianópolis. Aracaju, Goiânia e Florianópolis são as únicas cidades deste grupo que não estão diretamente conectadas à São Paulo. Caso se desconsidere a RNP na conformação desta sub-rede, o único efeito é a saída de Aracaju e Goiânia devido à redução de seus graus. Estas cidades passariam a fazer parte dos cores com menor quantidade de ligações. 
Para investigar os vértices de menor grau que estão mais firmemente ligados a este núcleo essencial, basta mudar o parâmetro dos k-núcleos, de modo a incluí-los. De acordo com as quebras naturais na distribuição da frequência dos nós, optou-se, em duas etapas, pelos 5-núcleo e 3-núcleo. No primeiro a sub-rede salta de 14 vértices para 40 e no segundo para 74, o que é, em realidade, uma ínfima parcela dos mais de cinco mil municípios que sequer figuram na presente rede. Este fato já é, sozinho, um indicador da centralidade daquelas cidades para o funcionamento físico da internet no país.

A diminuição dos parâmetros incluem os municípios da Região Metropolitana de São Paulo, as cidades mais populosas de Santa Catarina, bem como outros centros urbanos da região Sul, além dos vértices que realizam as conexões entre as regiões Norte e Nordeste (Imperatriz, São Luís, Belém e Teresina) e outros municípios do Nordeste e de Minas Gerais. $\mathrm{O}$ aumento do número de cidades conectadas nessas sub-redes faz aparecer caminhos alternativos ao nó mais central, nomeadamente São Paulo, o que dá à rede em geral - que funciona por comutação de pacotes - um caráter mais resistente por não depender de um único caminho.

Uma feição importante das estruturas em rede que também coube investigar é a existência de vértices funcionando como intermediários, isto é, servindo de ponte de ligação entre duas porções da rede. O subconjunto da rede, com no mínimo três nós, que não contém esse vértice de corte, isto é, não possua uma parte que possa ser desconectada pela remoção de algum nó, denomina-se bicomponente. Dentro do bicomponente não existe algum vértice específico que possa controlar o fluxo entre os nós, porque sempre há um caminho alternativo entre qualquer par de vértices. $O$ vértice de corte é definido, dessa maneira, como um intermediário entre duas porções da rede que, se ele não existisse, não se conectariam e estariam fisicamente isoladas.

A presença de vértices de corte, ou pontes de ligação, é sinal de que há gargalos na estrutura da rede pelo qual o fluxo deve necessariamente passar caso se queira atender a todos os nós. A verificação desses pontos de estrangulamento está apresentada na figura 3 , que marca a presença dos bicomponentes e das partes da rede que só se conectam através de intermediários. Neste grafo foi removido o bicomponente 0 , grupo contendo os nós que se ligam a apenas um vértice.

As ligações das redes backbones se estruturam de maneira a possuir três bicomponentes, tendo as cidades de Curitiba e Porto Alegre como seus intermediários, participando de todos. $\mathrm{O}$ primeiro corresponde aos municípios de Paranaguá e Antonina (PR), interligados entre si, mas dependentes da ligação com Curitiba para alcançar o restante da rede. O segundo bicomponente é praticamente a rede inteira, pois a maioria esmagadora dos vértices não têm ligações diretas com o Sul do país. Essa conexão se faz através do vértices de corte. A nuvem que compõe o segundo bicomponente significa que, apenas com esta exceção da região Sul, a maior parte das ligações backbones no Brasil não depende tão-somente de alguns poucos nós para manter sua conectividade, daí sua baixa legibilidade (foi removida a representação das ligações entre os nós do bicomponente 2 e os vértices de corte em virtude de seu elevado número, o que aumentaria significativamente a poluição visual do grafo).

O terceiro bicomponente corresponde ao estado do Rio Grande do Sul (parte superior direita da figura). As cidades gaúchas formam um cluster dependente da capital do estado para a sua ligação com o restante dos backbones do país.

\section{CENTRALIDADE DAS REDES DE BACKBONES}

O primeiro traço facilmente percebido da rede de backbones no Brasil, que compõe a dimensão física da internet, é a sua complexidade. Ela interliga centenas de municípios, muitos de maneira redundante, com diversas linhas conectando o mesmo par de cidades. Por outro lado, há dezenas de nós periféricos, dependentes de ligação com outros municípios para permanecerem na rede. Há estados com forte capilaridade e outros que não se conectariam se não fosse a capital. Existem linhas ligando aglomerações de nós, muito próximos uns aos outros, bem como aquelas que se estendem por várias centenas de quilômetros em áreas relativamente "vazias". 
Fonte: Elaboração do autor, com base no ATLAS BRASILEIRO DE TELECOMUNICAÇÕES, 2009

Mesmo com o caráter nebuloso de uma apreciação geral da rede, já é possível perceber o atendimento diferencial do território quanto ao provimento desse serviço. As maiores regiões metropolitanas, as regiões mais ricas e com maior densidade demográficas são as com melhor cobertura, maior quantidade de linhas e de pontos de presença. Nesse sentido, o caso brasileiro espelha o mesmo processo de outros países, onde a busca pela rentabilidade faz as companhias de telecomunicações darem preferência justamente a essas áreas com maior potencial de retorno dos investimentos (DUPUY, 2002; 2007; MALECKI, 2002; BERNARD, 2003).

Tendo em vista essa característica dos investimentos privados em redes de fibras óticas, o primeiro teste foi ponderar o quanto nossa análise poderia ser enviesada pela presença de uma rede pública (a RNP). Adicionando apenas dois nós (Boa Vista e Macapá), sua presença não trouxe modificação expressiva no grau de centralidade dos nós, com exceção de Brasília, cujo ranking subiu significativamente em termos de número de ligações. Este fato é, contudo, consistente com seu papel de sede dos poderes públicos, pelo qual se espera um maior peso da infraestrutura financiada pelo Estado.

Dada a variação dos níveis de cobertura do serviço no espaço, o instrumental da teoria dos gra- fos permitiu selecionar as partes das redes mais coesas, medir suas propriedades e classificar seus nós, tornando-a, assim, mais inteligível.

O cálculo dos índices de centralidade ratificou o que a primeira vista é claro: a rede de backbones possui alta centralização em São Paulo, que é o nó com o maior valor em ambos os índices (proximidade e intermediação). Uma explicação para isto é que, além da enorme demanda solvável de mercado pelo serviço, do ponto de vista dos operadores das redes seria financeiramente impraticável ligar todos os pontos entre si, ainda mais entre aqueles que implicariam em superar longas distâncias (WHEELER \& O'KELLY, 1999).

Em segunda posição em termos de importância, Curitiba desponta como nó, fortemente conectado a São Paulo e com alto nível de intermediação tanto pelo valor dos índices quanto por ser um vértice de corte interligando a região Sul ao restante do país.

A comparação dos valores das cidades de maior centralidade permitem algumas conclusões:

O Rio de Janeiro tem um índice de intermediação significativamente mais alto que Belo Horizonte. Isto é reflexo da posição da metrópole mineira em um ponto fisicamente mais central no país, que a dota de proximidade (closeness), enquanto que o grande número de linhas de incidentes ao Rio de Ja- 
neiro o faz ter um maior papel de intermediador na rede.

O caso particular de Cascavel é interessante porque é um nó aparentemente periférico, porém possui um índice de intermediação de valor elevado. Esta cidade, apesar do papel intermediador importante, não se constitui como vértice de corte em seu estado. Isto indica que, embora Cascavel faça parte do caminho mais curto entre os municípios do interior do Paraná e o restante da rede, também existem vias alternativas que dão a estes mais de uma opção de ligação - ao contrário do que acontece no Rio Grande do Sul, altamente centralizado na capital. O fato de dois municípios pequenos no Paraná, Paranavaí e Figueira, constarem na lista de cidades com os maiores índices de intermediação corrobora a presença dessas ligações alternativas. O índice de intermediação faz perceber, dessa maneira, que embora se encontre em uma posição relativamente menos importante na rede, Cascavel possui uma relevância regional para o seu estado. Na escala local, esse fato pode constituir um trunfo para a municipalidade, pois as cidades potencialmente se beneficiam em servir de $h u b$ regional na infraestrutura de telecomunicações. De acordo com as evidências apresentadas por Moss \& Townsend (2000), a estrutura espacial dos backbones é atraída por aglomerações de atividades econômicas baseadas na informação, as quais por sua vez atraem maior necessidade por este tipo de infraestrutura e serviços de telecomunicações, fazendo a localidade crescer na hierarquia de acessibilidade. Por outro lado, não há prova inequívoca de que simplesmente fornecer acesso a serviços de telecomunicações, como a internet, vá gerar desenvolvimento econômico, sendo, na melhor das hipóteses, um pré-requisito para a atração de negócios. De qualquer maneira, o sucesso da localidade irá depender tanto do movimento geral da rede quanto de sua trajetória específica e capacidade de criar atividades geradoras de valor.

No Nordeste, Salvador e Fortaleza se destacam com índices de proximidade praticamente idênticos, enquanto Recife se encontra em um patamar inferior. Esta situação é, de um lado, sintoma da maior proximidade da primeira capital com o Centro-sul - zona de maior densidade da rede. Por outro lado, a capital cearense é o ponto de conexão entre os dois grandes troncos de linhas de fibras óticas que vêm do Sudeste, um pelo litoral interligando as capitais nordestinas e o outro pelo eixo da rodovia Belém-Brasília, em que pesem os caminhos alternativos pelo interior. Além disso, Fortaleza serve como uma das pontes entre os backbones domésticos e os Estados Unidos e Caribe, via cabos submarinos (ATLAS BRASILEIRO DE TELECOMUNICAÇÕES, $o p$. cit.).

Fortaleza e Recife têm índices diferentes, embora se situem no mesmo nível na hierarquia urbana em geral (vide a pesquisa REGIC, IBGE, 2008). A primeira possui os dois índices maiores que a segunda, sendo que Recife não consta na tabela de municípios com maiores índices de intermediação, o que the evidencia um papel mais excêntrico na rede, consistente com sua posição no ranking dos acessos à internet (ver MOTTA, 2011)

Em relação à classificação dos vértices da rede de acordo com os núcleos coesos, nota-se uma coincidência entre o topo da hierarquia urbana e aqueles nós com forte coesão e grande número de ligações (grupo 7-núcleo), o que é consistente com a noção de que a internet mais reforça o papel das grandes cidades do que as solapa (MALECKI \& MORISET, 2008). A exceção às cabeças da rede urbana são os casos de Uberlândia e Aracaju. Contudo, essas cidades de porte médio, notadamente a primeira, possuem uma oferta de bens e serviços que lhes confere centralidade relativamente alta, e também, em se tratando de uma rede física que se dispõe horizontalmente no espaço, localizam-se na rota de passagem entre os centros urbanos mais populosos, o que as conferem um bom número de linhas de fibras óticas.

O grupo 5-núcleo, por sua vez, relativiza um pouco a extrema centralidade de São Paulo, fazendo transparecer uma série de caminhos alternativos à metrópole paulista. Por outro lado, a metrópole de São Paulo aparece bem representada por ter vários municípios que compõem sua região metropolitana incluídos no grupo. Estes acabam por constituir uma sub-rede máxima, altamente interconectada, fato que espelha as altas densidades demográficas e a concentração de renda da área. 
$\mathrm{Na}$ região Nordeste vale notar ainda o caso dos estados do Maranhão e do Piauí, que agrupam um conjunto de municípios bem conectados. Esta área em particular é percebida, a princípio, como pouco atraente em termos de rentabilidade em virtude do mercado pouco solvável, o que não justificaria a implantação de cabos de fibra ótica. Entretanto, o caráter redundante das conexões pode trazer mais estabilidade para o conjunto dos backbones no Norte e Nordeste, em uma escala mais ampla. Além dos investimentos privados na rede, nesse caso, a RNP também desempenha um papel não redundante nas ligações, ao contrário do Centro-sul. Caso ela fosse removida da topologia da rede, a ligação daquelas cidades com o restante da rede veria o papel de Fortaleza fortalecido devido à remoção da ligação direta de São Luís com o Rio de Janeiro e da diminuição do grau de Recife.

A classificação dos vértices em bicomponentes, por sua vez, clarificou a presença das partes da rede que dependem de alguns nós para sua interligação com o restante. Marcou a importância das cidades de Porto Alegre e Curitiba como grandes intermediadores nacionais, fazendo a interligação de diversos municípios na região Sul com a maior parte do país. No estado do Rio Grande do Sul, particularmente, sua capital é um ponto de passagem quase exclusivo para os municípios do interior. A última pesquisa Região de Influência de Cidades (REGIC) (IBGE, op. cit.) mostrou uma elevada centralização no nível estadual, e aqui se demonstra que isso também é verdadeiro no caso das redes de transmissão de dados.

\section{CONSIDERAÇÕES FINAIS}

Já se escreveu muito sobre a importância de se estar conectado nas redes, frequentemente tratando-as de maneira binária - ausência x presença; conexão x desconexão. Porém, mesmo entre os "conectados", o caráter relativo de sua posição em relação aos demais determina suas possibilidades, pois além de algumas posições serem mais influentes que outras, cada ponto interage de maneira distinta e mediada com o conjunto de uma rede (SHEPARD, 2002). No que tange aos backbones, essa posicionalidade afeta a forma com que a rede é desfrutada. As cidades com pouca centralidade e acessibilidade estão em desvantagem na medida em que o maior número de passos necessários para que o tráfego as atinja aumenta sua latência. Embora, do ponto de vista do usuário individual, o aumento de alguns milissegundos de demora no envio ou recebimento de mensagens não cause impacto, o efeito agregado de milhões de mensagens pode degradar a performance da rede, impondo não só um custo de tempo mais também uma potencial perda de informações (MALECKI \& MORISET, op. cit.).

A rede de backbones no Brasil mostra uma elevada robustez porque, a despeito de sua centralização, há diversos caminhos alternativos e redundantes. Estes são vitais em caso de falhas e de congestão em certos nós, que podem causar problemas de acesso em certas áreas e mesmo desconexão de vértices, porém mantém a maior parte da rede funcionando, tal como foi projetada sua arquitetura. Isto pôde ser comprovado em algumas ocasiões, como no dia 03 de julho de 2008, quando problemas na rede da companhia Telefônica deixaram um sem-número de usuários individuais, empresas e entidades públicos desconectados no estado de São Paulo. Apesar das falhas acontecerem em nós centrais, o problema sequer foi sentido nos outros estados, pois o tráfego de pacotes pôde tomar aqueles caminhos alternativos.

Com efeito, comparando a complexidade da geografia dos backbones nacionais com outros países onde eles se configuram de maneira mais simples, fica clara que sua diversidade reflete a complexidade econômica onde se insere: Em Burkina Faso, o backbone se resume a cinco cidades conectas diretamente à capital Ouagadougou, que serve como intermediador de todos os pontos do território; em Senegal apenas duas cidades são responsáveis pela interligação do território (BERNARD, 2003).

Manter uma acessibilidade relativamente mais direta em relação às outras localidades na rede continua sendo um elemento-chave na vida econômica, de maneira semelhante ao papel que as malhas rodoviária, ferroviária, telegráfica e telefônica desempenharam em momentos históricos anteriores. A Internet, como um meio mais recente de trocas de bens informacionais não se mostra, em sua dimensão das ligações físicas, como uma niveladora do espaço, 
sendo profundamente diferenciada. Portanto, manter a capacidade de conexão em um momento de aumento de importância das transações por meios digitais, atraindo conectividade por backbones, é um componente central para a competitividade.

\section{REFERÊNCIAS}

ATLAS BRASILEIRO DE TELECOMUNICACOES. São Paulo: Converge Comunicações, 2009.

BERNARD, E. Le déploiement des infrastructures internet en Afrique de l'Ouest. Montpellier: Université Montpellier III - Paul Valéry. Thèse Arts et Lettres, Langues et Sciences Humaines et Sociales, Doctorat Géographie: Mutations spatiales, 2003.

CAIRNCROSS, F. O fim das distâncias: como a revolução nas comunicações transformará nossas vidas. São Paulo: Nobel, 2000.

CASTELLS, M. A sociedade em rede. São Paulo: Paz e Terra, 1999.

DIAS, L. C. Redes: emergência e organização. In: CASTRO, I. et al (orgs.). Geografia: Conceitos e temas. Rio de Janeiro: Bertrand Brasil, 1995, p. 141-162.

DODGE, M. \& KITCHIN, R. Atlas of Cyberspace. Harlow: Pearson Education, 2001.

DUPUY, G. La fracture numérique. Paris: Ellipses, 2007.

. Internet: une approche géographique a

l'echelle mondiale. Flux, n 58 , p. 5-19. Bû: Métropolis, 2004.

. Internet: géographie d'un réseau. Paris: El-
EVENO, E. \& PUEL, G. Villes et nouvelle économie. Mappemonde, $\mathrm{n}^{\circ}$ 70, p. 1-6. Avignon: UMR ESPACE, 2003.

GRUBESIC, T. \& O'KELLY, M. Backbone topology access, and the commercial internet, $1997-2000$. Environment and Planning B: Planning and Design, vol. 29, p. 533-552. London: Pion, 2002.

IBGE. Regiões de Influência de Cidades 2007. Rio de Janeiro: IBGE, 2008.

MALECKI, E. The economic geography of the Internet's infrastructure. Economic Geography, 78(4), p. 399-424. Worcester, MA: Clark University, 2002.

MALECKI, E. \& MORISET, B. Digital economy. Business organization, production processes and regional development. London and New York: Routledge, 2008.

MOSS, M. L. \& TOWNSEND, A. M. The internet backbone and the American metropolis. The information society, $\mathrm{n}^{\circ} 16$, p. 35-47. Florence, Kentuck: Taylor \& Francis, 2000.

MOTTA, M. P. Geografia da internet no Brasil: Redes técnicas e espaço. Rio de Janeiro: UFRJ/PPGG. Tese de doutorado, 2011.

NEGROPONTE, N. Being rural. Wired Magazine, 7(06), 1999. Disponível em <http://www.wired.com/ wired/archive/7.06/mustread.html?pg=14>. Acesso em 28/12/2011.

NOOY, W.; MRVAR, A. \& BATAGELJ, V. Exploratory social network analysis with Pajek. New York: Cambridge University Press, 2005. lipses. 2002. 
PESQUISA SOBRE O USO DAS TECNOLOGIAS DA INFORMAÇÃO E COMUNICAÇÃO NO BRASIL: 2005-2009. São Paulo: Comitê Gestor da Internet no Brasil, 2010.

SHEPPARD, E. The spaces and times of globalization: Place, space, networks and positionality. Economic Geography, 78(3), p. 307-330. Worcester, MA: Clark University, 2002.

TRANOS, E. \& GILLESPIE, A. The spatial distribution of Internet backbone networks in Europe: A metropolitan knowledge economy perspective. European Urban and Regional Studies, 16(4), p. 426-43. Thousand Oaks, CA: Sage, 2009.

WHEELER, D. \& O'KELLY, M. Network topology and city accessibility of the commercial internet. Professional Geographer, 51(3), p. 327-339. Malden, MA: Balckwell, 1999.

ZOOK, M. The geography of internet industry. Malden, MA: Blackwell, 2005.

. Old hierarchies or new networks of centrality? - The global geography of internet content market. American Behavioral Scientist, 44(10), p. 1679-1696. Thousand Oaks, CA: Sage, 2001a.

. Connected is a matter of geography. NetWorker, 5(3), p. 13-17. New York: ACM, 2001 b. 